RESEARCH

Turkish Journal of Geriatrics

DOI: 10.31086/tigeri.2020.159

2020; 23(2): 241-250

- Betül DUMAN BAY'

- Murat ŞENTÜRK² (D)

- Mustafa OTRAR ${ }^{3}$ D

- Zuhal GÜLER ${ }^{4}$ (D)

CORRESPONDANCE

Betül DUMAN BAY

Y.ldız Technical University, Humanities and Social Sciences, İstanbul, TURKEY.

Phone: +905323336546

e-mail: betulduman@hotmail.com

Received: January 27, 2020

Accepted: May 08, 2020

${ }^{1}$ YIddz Technical University, Humanities and Social Sciences, İstanbul, TURKEY.

2 Istanbul University, Sociology, İstanbul, TURKEY.

${ }^{3}$ The Ministry of National Education, Ankara, TURKEY.

${ }^{4}$ Abant lzzet Baysal University, Sociology, Bolu, TURKEY.

\section{EXPECTATIONS OF ELDERLY PEOPLE REGARDING URBAN RENEWAL BASED ON THEIR CULTURAL CAPITAL: THE CASE OF ISTANBUL}

\section{Abstract}

Introduction: This study analyzes expectations of the elderly (over 65 years of age) residents of Istanbul regarding urban renewal on the basis of their cultural capital. The literature review indicated that a very limited number of studies existed that focused on urban renewal while considering elderly people's views. In those studies, the elderly often is either treated as a homogenous group or separated on the basis of their ethnicity and/or socioeconomic status. Therefore, this study was conducted to fill an important gap in the literature, namely that the analysis of the differentiation of urban renewal expectations of the elderly based on their cultural capital.

Materials and Methods: The data were collected via face-to-face surveys conducted with 1818 elderly people in 20 districts. In this study, cultural capital was operationalized in line with the embodied and institutionalized aspects as well as the taste dimension. Moreover, an urban renewal expectations scale was developed, and a one-way analysis of variance was carried out among the elderly based on their cultural capital and their scores in the urban renewal expectations scale.

Results: The study highlights elderly people's expectations of urban renewal with regard to their economic profits and the physical and social improvement of the housing and environment in which they live.

Conclusion: The low-cultural capital group has been identified as the most fragile group, and the negative consequences of urban renewal that may result in displacement, family division, and isolation have been emphasized.

Keywords: Aged; Population dynamics; Loneliness; Urban renewal; City planning. 


\section{INTRODUCTION}

This study analyzes how individuals' (over 65 years of age and living in Istanbul) expectations regarding urban renewal (UR) differ on the basis of their cultural capital (CC). Istanbul provides valuable information in this respect because of both the proportion of the elderly living there and the rapid and large-scale experience of UR in the city. According to 2018 data, 1,006,545 people over the age of 65 live in Istanbul, corresponding to a share of $14 \%$ of the total elderly population in Turkey (1).

While the elderly spends a significant part of their daily lives at home, they are more sensitive to the effects of transformation. Few studies discuss the issue of UR and the elderly, and they belong to the post-2000 period. Several studies underlined the negative effects of UR on the body and the mind caused by effects such as large-scale displacement, dormant buildings, closure of local enterprises, and long-term and large uncertainties of transformation $(2,3)$. The consequences of displacement include the elderly's loss of social networks and supportive relationships, loss of sense of belonging and commitment to the place, and loneliness $(4,5)$. Few studies analyze the impact of old age on quality of life. For example, Scharf et al. $(6,7)$ conducted their study with 600 people over the age of 60 in Liverpool, London, and Manchester, and they found that the elderly had a strong sense of exclusion, that almost half of the elderly they interviewed experienced poverty, and that a considerable proportion of the elderly experienced loneliness. The elderly who belong to ethnic minorities face more disadvantages. The insecurity among the elderly living in poor neighborhoods is more intense because of high crime rates in such neighborhoods, limited access to services, and poor physical environmental conditions, consequently making it more difficult for them to go out.

International studies treat the elderly as a homogenous group and rarely pay attention to ethnicity and/or socioeconomic status. Therefore, analyzing the elderly's expectations of UR on the basis of their CC is bound to make a significant contribution to the literature. The data analyzed in the present study were collected via surveys administered face-to-face with 1818 elderly residing in 20 different districts of Istanbul.

The study consists of three sections. In the first section, the definition and indicators of CC and details regarding the research population and sample are explained. In the next section, the UR expectations scale is presented, and the results of its validity and reliability analyses are described. In addition, the results of statistical analyses conducted between the CC and the UR expectations scale are provided. The low-CC group is identified as the most fragile. Moreover, the negative consequences of UR that can lead to displacement and isolation are emphasized. In the Conclusion section, findings of the present study are compared with the literature and their implications are highlighted.

\section{MATERIALS AND METHOD}

\section{Cultural Capital}

Bourdieu defines CC as "the styles of knowledge, talent, taste, and education that one acquires and the benefits that one achieves thanks to them." CC, according to Bourdieu, has three forms: embodied CC (e.g., the knowledge of a foreign language or speech and writing style); objectified CC (e.g., pictures, books, and paintings); and institutionalized CC (e.g., diplomas and certificates) (8).

Sociology research has generally adopted two different approaches to measure CC (9). The first approach is the measurement of CC regarding the level of completed education, which is an institutionalized form. This approach, however, was criticized because it ignores the issue of 
taste. The second approach is the definition and measurement of traditionally elite cultural consumption practices. Indicators such as visiting museums, going to operas, visiting galleries, and going to classical music concerts are considered. Naturally, these elements of high culture are based on the assumptions of cultural legitimacy, and the nature of this cultural legitimacy can change from one period of time to another and from one geography to another.

Arun (10) examined CC in two dimensions. The first dimension was measured by the level of education, foreign language knowledge, participation in training/courses, place of living, and living opportunities (e.g., taking vacations, going out for dinner, and possibilities for cultural expenditure). The second dimension was measured by participation in political and cultural activities and level of social bonding (10). For example, in the Antalya Old Age Survey conducted in 2013, it was found that the elderly who were in upperclass positions had higher levels of self-respect and will-to-live, participated in the high cultural events extensively, and used technological items more frequently in their lives (11).

In the present study, the variables that relate to the measurement of CC were determined as the following: learning status, foreign language knowledge, budget allocation to sociocultural expenditures, vacation places, the frequency of going out for cultural purposes, and the frequency of participation in cultural activities such as sports-cinema-theater-concert-art gallery. In terms of education; 0 points were given to those who were illiterate or only literate; 1 point was given to primary and secondary school graduates; and 2 points were given to those with a high school diploma and qualifications above that. In addition, 2 points were awarded to those who reported being able to speak a foreign language and 2 points were given to those who spend their holidays abroad or in a resort/hotel. In terms of participation in cultural events; participants were awarded $0,-1$, or -2 according to how frequently they participated in those events. It has been observed that the scoring table is compatible with the education level table.

In addition, the birthplace variable was added to determine access to educational opportunities; those born in Istanbul and those who came to Istanbul between 1930 and 1950 were given 1 point and the others were given 0 points (10). As a variable showing lifestyle habits, the question focusing on "the most frequent place to meet with friends" was considered. Consequently, those who answered the question as "restaurant and café" received 1 more point, and the rest received 0 points for their total CC score. In this framework and within the scope of all variables, the CC score was defined as "low" for those who scored between 1 and 5 points; "medium" for those who scored between 6 and 10 points, and "high" for those who scored between 11 and 22 points.

\section{Population, Sampling, and Data Collection Tools}

The population of the research consisted of elderly individuals (aged 65 and over) residing in Istanbul. The creation of the sample $(N=1818)$ included the stages of calculating the minimum sample size for Istanbul first and then recruiting participants following a stratified sampling strategy in line with the elderly population ratio in different districts. Afterwards, the purposive sampling method was utilized on the basis of individuals' experiences of UR (realized, ongoing, publicdecision-based, or individual-decision-based UR). The districts and related neighborhoods were identified in line with this data, and the sample distribution was made on the basis of their elderly ratios.

In addition to the literature review, the data collection tool was developed on the basis of 59 in-depth interviews with actors in Istanbul, such as municipal authorities and neighborhood 
representatives. Following the approval of the data collection tool by the Ethics Committee of Istanbul University on 26th December in 2016 (Decision no: 29), 17 expert researchers on old age, aging, and UR were consulted. The data collection tool was revised according to experts' opinions, tested in a pilot study, and revised in consideration of the problems encountered. Field researchers were trained, and they were tasked with data collection. They started from a specific starting point in their neighborhood and moved on to another building when they managed to conduct the survey with an appropriate participant. Interviews were conducted in homes and/or gardens of elderly individuals. The data obtained from the field study were analyzed using the SPSS Quantitative Data Analysis Software.

\section{Urban renewal expectations scale}

When creating the UR expectations scale, the answers of the 1818 people who constituted the sample were considered and factor analysis was carried out by considering all the variables thought to measure expectations. Multi-stage exploratory factor analyses (EFA) showed that the KMO value of the scale was 0.889 , indicating the suitability of the data for EFA. According to Tabachnick and Fidell (12), the closer the $\mathrm{KMO}$ value is to 1 , the more suitable the data becomes for factor analysis. Multi-stage factor analysis processes performed following principal component analysis and the Varimax rotation technique indicated that a number of items loaded onto multiple factors. Among these items, those with less than $10 \%$ factor load difference were eliminated, and the factor analysis was repeated. The final scale was found to consist of seven factors with an eigenvalue of more than 1.00 , explaining $52.589 \%$ of the total variance. The seven factors that constitute the scale were distinguished and identified (Table 1). Subsequently, the reliability analysis of the scale was completed. Accordingly, the internal consistency reliability of the scale was calculated using the Cronbach Alpha coefficient, and the value was found to be 0.590 .

\section{RESULTS}

Descriptive analyses of the sample concerning different variables based on their cultural capital

In total, $70.2 \%$ of the elderly were found to have low CC; $20.7 \%$ had medium CC; and 9.1\% had high CC (Table 2).

While $1.2 \%$ of the elderly in the low-CC group were never married or single, the proportion of this subgroup among the high-CC owners increased to $7.4 \%$. In addition, the $32.6 \%$ of the elderly in the low-CC group and $25.9 \%$ of the elderly in the highCC group were either divorced or their partners had passed away.

More than three-quarters of those in the lowCC group had three or more children, while $76.4 \%$ of the elderly in the high-CC group did not have any children or had up to two children. It is worthwhile to note that those in the low-CC group had multi-children families.

Of those in the low-CC group and those in the high-CC group, $93.6 \%$ and $67.7 \%$ were immigrants, respectively.

Of those in the high-CC group, 56.9\% were employed in professional jobs, while $37 \%$ had worker/employee status. A total of $62.7 \%$ of employers were in the low-CC group, while $85.6 \%$ of housewives were in the low-CC group.

Overall, $89 \%$ of those earning 1000TL and below; $80.8 \%$ of those earning between $1001 \mathrm{TL}$ and 2000TL; $42.2 \%$ of those earning between 4001 and $5000 T L$; and $28.6 \%$ of those earning $5001 \mathrm{TL}$ or more were in the low-CC group. Thus, this relationship between average monthly income and $\mathrm{CC}$ indicates that the convertibility of the economic capital and the CC is considerably high.

Moreover, $16.9 \%$ of those in the low-CC group 
Table 1. Urban Renewal Expectations Scale.

\begin{tabular}{|c|c|}
\hline Items & Sub-dimension titles \\
\hline E10h Urban renewal (UR) makes me feel valuable & \multirow{6}{*}{$\begin{array}{l}\text { The expectation of improvement in socio- } \\
\text { spatial relations dimension ( } 6 \text { items) }\end{array}$} \\
\hline E10e I have a better time in my neighborhood thanks to UR & \\
\hline E10g UR creates places where I can spend more time with my family & \\
\hline E10b UR improves the neighborhood culture & \\
\hline E10m I can host my guests better thanks to UR & \\
\hline E10j UR brings new neighbors in & \\
\hline E10z UR changes my habits & \multirow{7}{*}{$\begin{array}{r}\text { Anxiety about change dimension } \\
\text { (7 items) }\end{array}$} \\
\hline E10d It is hard to get used to the lifestyle after the UR & \\
\hline E10r I am disturbed by the new residents who came after the UR & \\
\hline E10y UR destroys my memories & \\
\hline E10s UR worries me & \\
\hline E10c I feel worthless when I'm not asked for my opinion on UR & \\
\hline E10t Neighborhood security decreases with newcomers & \\
\hline E10ab UR causes many people to relocate & \multirow{3}{*}{$\begin{array}{r}\text { The dimension of alienation-decreasing } \\
\text { acquaintance } \\
\text { (3 items) }\end{array}$} \\
\hline E10aa The number of people I know locally decreases after UR & \\
\hline E10p UR increases the distance with existing neighbors & \\
\hline E10ar I return to my hometown after UR & \multirow{2}{*}{$\begin{array}{r}\text { Displacement dimension } \\
\text { ( } 2 \text { items) }\end{array}$} \\
\hline E10o I leave my neighborhood due to UR & \\
\hline E10k UR does not make any financial contribution to my budget & \multirow{2}{*}{$\begin{array}{r}\text { Economic profit dimension } \\
\text { ( } 2 \text { items) }\end{array}$} \\
\hline E10ah I do not care about the increase in the economic value of my house after UR & \\
\hline E10ag UR is only beneficial for young people & \multirow{2}{*}{$\begin{array}{r}\text { Rejuvenation dimension } \\
\text { ( } 2 \text { items) }\end{array}$} \\
\hline E10ao UR rejuvenates the neighborhood's population & \\
\hline E10am The number of common areas should increase following UR & \multirow{3}{*}{$\begin{array}{r}\text { Population density dimension } \\
\text { ( } 3 \text { items) }\end{array}$} \\
\hline E10I UR increases the crowdedness & \\
\hline E10a Crowds make it difficult to live in the city & \\
\hline
\end{tabular}

and $3.2 \%$ of those in the high-CC group suffered from poor overall health.

\section{Findings of one-way analysis of variance}

One-way analysis of variance (ANOVA) was conducted between CC scores and UR expectations of participants (see Table 3). After determining whether there was any significant difference following the administration of ANOVA, complementary post-hoc analysis techniques were utilized to identify the groups that were the origins of significant differences. To decide upon which post-hoc multiple comparison technique to use, the hypothesis as to whether the variances of the group distributions were homogeneous was tested using Levene's test. It was found that the variances were homogeneous. Afterwards, the LSD multiple comparison technique, which is widely used when variances are homogeneous, was preferred (Table 4). The findings can be summarized as follows:

1. The expectation of socio-spatial improvement after UR varies significantly by participant score of CC $(p<0.05)$. The difference is present between the low- and medium-, low- and high-, and medium- and high-CC 
Table 2. Cultural Capital Group.

\begin{tabular}{|l|r|r|r|r|}
\hline Groups & F & \% & Valid\% & Cumulative \% \\
\hline Low & 1277 & 70,2 & 70,2 & 70,2 \\
\hline Medium & 376 & 20,7 & 20,7 & 90,9 \\
\hline High & 165 & 9,1 & 9,1 & 100,0 \\
\hline Total & 1818 & 100,0 & 100,0 & \\
\hline
\end{tabular}

Table 3. Results of ANOVA Analysis.

\begin{tabular}{|c|c|c|c|c|c|c|c|}
\hline Scores & Groups & $\mathbf{N}$ & $\bar{x}$ & ss & sh & $F$ & $p$ \\
\hline \multirow{4}{*}{$\begin{array}{l}1 \text { The expectation of improvement in socio- } \\
\text { spatial relations }\end{array}$} & Low & 1220 & 2,17 & 63 & ,02 & \multirow{4}{*}{21,200} & \multirow{4}{*}{, 000} \\
\hline & Medium & 409 & 2,05 & ,65 &, 03 & & \\
\hline & High & 189 & 1,86 & 65 &, 05 & & \\
\hline & Total & 1818 & 2,11 & 64 & ,02 & & \\
\hline \multirow{4}{*}{2 Anxiety about change } & Low & 1220 & 2,15 &, 54 & ,02 & \multirow{4}{*}{14,570} & \multirow{4}{*}{, 000} \\
\hline & Medium & 409 & 2,00 &, 56 &, 03 & & \\
\hline & High & 189 & 1,99 &, 56 &, 04 & & \\
\hline & Total & 1818 & 2,10 &, 55 & 01 & & \\
\hline \multirow{4}{*}{3 Alienation effect } & Low & 1220 & 2,50 &, 57 &, 02 & \multirow{4}{*}{4,477} & \multirow{4}{*}{011} \\
\hline & Medium & 409 & 2,44 & ,62 & ,03 & & \\
\hline & High & 189 & 2,38 & 61 &, 04 & & \\
\hline & Total & 1818 & 2,47 &, 59 &, 01 & & \\
\hline \multirow{4}{*}{4 Displacement effect } & Low & 1220 & 1,41 &, 59 &, 02 & \multirow{4}{*}{4,520} & \multirow{4}{*}{011} \\
\hline & Medium & 409 & 1,33 &, 53 & ,03 & & \\
\hline & High & 189 & 1,31 &, 52 &, 04 & & \\
\hline & Total & 1818 & 1,38 &, 57 & 01 & & \\
\hline \multirow{4}{*}{5 Expectation of economic profit } & Low & 1220 & 2,11 & 69 &, 02 & \multirow{4}{*}{3,564} & \multirow{4}{*}{, 029} \\
\hline & Medium & 409 & 2,01 & ,75 &, 04 & & \\
\hline & High & 189 & 2,01 & ,74 &, 05 & & \\
\hline & Total & 1818 & 2,07 & ,71 &, 02 & & \\
\hline \multirow{4}{*}{6 Young-age suitability } & Low & 1220 & 2,12 & 64 &, 02 & \multirow{4}{*}{19,092} & \multirow{4}{*}{, 000} \\
\hline & Medium & 409 & 2,00 & 63 &, 03 & & \\
\hline & High & 189 & 1,83 & ,62 & ,05 & & \\
\hline & Total & 1818 & 2,06 & 64 & ,02 & & \\
\hline \multirow{4}{*}{7 Density/crowd perception } & Low & 1220 & 2,80 &, 33 & 01 & \multirow{4}{*}{7,347} & \multirow{4}{*}{001} \\
\hline & Medium & 409 & 2,85 &, 31 &, 02 & & \\
\hline & High & 189 & 2,87 &, 29 &, 02 & & \\
\hline & & 1818 & 2,82 & ,32 &, 01 & & \\
\hline
\end{tabular}


groups. The elderly grouped under low CC expect the most and the elderly grouped under high CC expect the lowest socio-spatial improvement. The expectation of socio-spatial improvement is influenced by factors such as the improvement of the neighborhood culture after UR; the increase in the potential to have a good time with the family; hosting guests more comfortably; and feeling the self to be more valuable. The low average scores in this dimension for the elderly in the high-CC group are interrelated with the neighborhood in which they live, housing comfort, and (dis)satisfaction they feel from those.

2. The anxiety regarding the change caused by UR based on CC scores of the elderly differs significantly $(p<0.05)$. This differentiation is present between low and medium and between low and high-CC groups. Accordingly, the average concern of those in the low-CC group in relation to UR is higher than the average concerns of those in the other two groups. These concerns include the change of habits because of UR, the difficulty of adjusting to a new lifestyle, the disappearance of memories, and the disturbance caused by the newly arrived residents.

3. The alienation-diminishing acquaintance effect of UR varies significantly on the basis of participants' CC scores ( $p<0.05$ ). This difference is present between the low- and medium-CC groups and the low and highCC groups. Accordingly, the elderly in the low-CC group are the ones who expect the alienating effect of UR the most. This indicates the decrease of acquaintances and neighbors of elders with low CC in newly produced urban spaces and their conviction that they will not be able to adapt to the new neighborhood. It is also important to note that family sizes change after UR and that families of 4, 5, and 6 people have to return to apartments designed for 1,2 , or 3 people. This is caused by the reduction of housing sizes.

4. The displacement effect that may develop from UR varies significantly based on the elderly's scores of CC ( $p<0.05)$. This difference is present between the low and medium and the low- and high-CC groups. The elderly in the low-CC group are more likely to relocate as a reaction.

5. The expectation of economic profit varies significantly across different CC groups ( $p$ $<0.05)$. This difference is present between the low- and medium-CC groups, and the economical expectations of the elderly in the medium-CC group are higher than those of the elderly in the low-CC group.

6. Opinions on the suitability of UR for young people vary significantly across different CC groups $(p<0.05)$. This difference is present between the low- and medium-, the low- and high-, and the medium- and high-CC groups. The elderly from the low-CC group most strongly and the elderly from the highest CC group least strongly believe that UR is more suitable for the youth.

7. Participants' expectations regarding the crowd/ density effect of UR differ significantly across different CC groups ( $p<0.05$ ). Accordingly, the average scores of the elderly in the low-CC group regarding the expectation that UR will produce crowdedness and condensation are lower than those of the elderly in the mediumand high-CC groups. No significant difference was found between the scores of the elderly in the low- and high-CC groups.

\section{CONCLUSION}

The present study investigated how the expectations of individuals over 65 years of age differ on the basis of their CC. The results of other studies on UR overlap with some of the findings of 
Table 4. LSD Multiple Comparisons Analysis

\begin{tabular}{|c|c|c|c|c|c|}
\hline Scores & Group (I) & Group (J) & Avg. Diff. (I-J) & sh & $\mathrm{p}$ \\
\hline \multirow{6}{*}{$\begin{array}{l}1 \text { The expectation of improvement in } \\
\text { socio-spatial relations }\end{array}$} & \multirow{2}{*}{ Low } & Medium &, 12 & ,04 &, 001 \\
\hline & & High &, 30 & 05 &, 000 \\
\hline & \multirow{2}{*}{ Medium } & Low &,- 12 &, 04 &, 001 \\
\hline & & High &, 18 &, 06 &, 001 \\
\hline & \multirow{2}{*}{ High } & Low &,- 30 &, 05 &, 000 \\
\hline & & Medium &,- 18 &, 06 &, 001 \\
\hline \multirow{6}{*}{2 Anxiety about change } & \multirow{2}{*}{ Low } & Medium &, 14 & ,03 &, 000 \\
\hline & & High &, 16 &, 04 &, 000 \\
\hline & \multirow{2}{*}{ Medium } & Low &,- 14 &, 03 &, 000 \\
\hline & & High &, 01 &, 05 &, 795 \\
\hline & \multirow{2}{*}{ High } & Low &,- 16 &, 04 &, 000 \\
\hline & & Medium &,- 01 &, 05 &, 795 \\
\hline \multirow{6}{*}{3 Alienation effect } & \multirow{2}{*}{ Low } & Medium &, 06 & ,03 & ,073 \\
\hline & & High &, 12 & ,05 & ,007 \\
\hline & \multirow{2}{*}{ Medium } & Low &,- 06 & ,03 & ,073 \\
\hline & & High &, 06 &, 05 & ,223 \\
\hline & \multirow{2}{*}{ High } & Low &,- 12 &, 05 &, 007 \\
\hline & & Medium &,- 06 &, 05 &, 223 \\
\hline \multirow{6}{*}{4 Displacement effect } & \multirow{2}{*}{ Low } & Medium &, 08 &, 03 & 013 \\
\hline & & High &, 09 &, 04 & 035 \\
\hline & \multirow{2}{*}{ Medium } & Low &,- 08 & ,03 & 013 \\
\hline & & High &, 01 & 05 &, 796 \\
\hline & \multirow{2}{*}{ High } & Low &,- 09 &, 04 & ,035 \\
\hline & & Medium &,- 01 & ,05 & ,796 \\
\hline \multirow{6}{*}{5 Expectation of economic profit } & \multirow{2}{*}{ Low } & Medium &, 09 &, 04 & ,024 \\
\hline & & High &, 10 &, 06 & 071 \\
\hline & \multirow{2}{*}{ Medium } & Low &,- 09 &, 04 & ,024 \\
\hline & & High &, 01 &, 06 &, 896 \\
\hline & \multirow{2}{*}{ High } & Low &,- 10 &, 06 & ,071 \\
\hline & & Medium &,- 01 &, 06 &, 896 \\
\hline \multirow{6}{*}{6 Young-age suitability } & \multirow{2}{*}{ Low } & Medium &, 12 &, 04 &, 001 \\
\hline & & High & ,29 &, 05 &, 000 \\
\hline & \multirow{2}{*}{ Medium } & Low &,- 12 &, 04 & ,001 \\
\hline & & High &, 17 &, 06 &, 003 \\
\hline & \multirow{2}{*}{ High } & Low &,- 29 &, 05 &, 000 \\
\hline & & Medium &,- 17 &, 06 &, 003 \\
\hline \multirow{6}{*}{7 Density/crowd perception } & I OWw & Medium &,- 05 & ,02 & ,003 \\
\hline & Low & High &,- 07 & ,03 &, 003 \\
\hline & Medium & Low & ,05 & ,02 & ,003 \\
\hline & Medium & High &,- 02 & 03 & ,484 \\
\hline & & Low &, 07 & ,03 &, 003 \\
\hline & High & & ,02 & ,03 & ,484 \\
\hline
\end{tabular}


the present research. For example, it is shown that UR in Istanbul, in general, has become operational as an economic gain-oriented process; it is known that all sides of this process also see their residences as investment tools and their main motivation is to increase their economic profit as much as possible (13). This motivation, which is established by the income axis of UR in Istanbul, does not differ among the elderly. However, it can be said that this motivation is embraced slightly more by people who belong to the high-CC group.

Although UR is encouraged by economic profits, it is also perceived as a process that increases fears and anxieties of the elderly. It can be argued that what makes the UR more acceptable for the elderly could be related to the fact that the elderly evaluates the benefits for their children more than they do for themselves.

In line with their CC, it is assessed that two types of displacement tendencies may occur among the elderly. The first trend is the tendency of low CC owners to be displaced more forcefully owing to the fact that they also mainly belong to the lower economic classes. The possible reasons for displacement are predicted to be the following:

a) The downsizing of the houses might not be compatible with the existing family structure,

b) They could be motivated to buy housing from more peripheral locations to utilize the decreased expenses for a smaller house so that they could make their children a homeowner, or

c) They might rent or sell their house because of the expected lifestyle differences between the current and the new one.

The other trend is voluntary displacement, which can be observed mostly among the elderly in the high-CC group. Those who live in the city center or the inner city can permanently move to the places at the periphery during and after the UR so as to avoid negative effects such as noise, traffic congestion, air pollution, and crowds. Moreover, they could then rent their old dwellings to the middle classes, thereby increasing their income. Another result of such a process is that the high-CC group ends up contributing to the gentrification of the periphery. For the elderly, displacement means the loss of the familiar physical and social environment and relationships. The negative effects of displacement caused by UR become more visible when one pays attention to research on spatial practices and the benefits of getting older in the same place, such as easier everyday life (14).

The elderly from the low-CC group are the ones who expect the alienation effect of UR the most. This means that those people expect that they will be lonelier in the newly produced space; will have fewer neighbors; and will be unable to conform to the newly formed neighborhood. In addition, it should be stated that family sizes change after UR in that drastic reduction of housing sizes leads to this outcome by causing families of 4,5 , or 6 people to return to apartments designed for 1 , 2 , or 3 people. This might cause more loneliness for the elderly belonging to the low-CC group. The alienating and isolationist effect of UR on the elderly is also compatible with international literature (15).

\section{ACKNOWLEDGMENT}

This paper is based on the data obtained during the "Urban Regeneration and Ageing in Metropolitan Areas: The Case of Istanbul" Project (117K296) funded by TUBITAK (The Scientific and Technological Research Council of Turkey). 


\section{REFERENCES}

1. Ministry of Family, Labour and Social Services. General Directorate of Disabled and Elderly People. Statistical Bulletin of Disabled and Elderly. 2019. [Internet] Available from: https://ailevecalisma.gov. tr/media/11564/eyhgm_buelten_temmuz2019.pdf. Accessed:10.11.2019.

2. Davidson G, McGuinness D, Greenhalgh P, Braidford $P$, Robinson F. It'll get worse before it gets better; local experiences of living in a regeneration area. $J$ Urban Regeneration and Renewal 2013;7(1):59-70.

3. Kearns A, Mason P. Defining and measuring displacement; is relocation from restructured neighborhoods always unwelcome and disruptive? Housing Studies 2013;28(2):177-204. (DOI: 10.1080/02673037.2013.767885).

4. Kearns A, Whitley E, Tannahill C, Ellaway, A. Loneliness, social relations and health and wellbeing in deprived communities. Psychol Health Med 2015;20(3):332-44. (PMID: 25058303).

5. Goetz EG. Desegregation in 3D; displacement, dispersal and development in American public housing. Housing Studies 2010;25(2):137-58. DOI: 10.1080/ 02673030903561800.

6. Scharf T, Phillipson C, Smith A. Older people's perceptions of the neighborhood; evidence from socially deprived urban areas. Sociological Research Online 2003;8(4):153-164. (DOI: 10.5153/sro.867).

7. Thomas Scharf, Chris Phillipson, Allison E. Smith, Paul Kingston. Growing Older in Socially Deprived Areas: Social Exclusion in Later Life. 1st Edition, Help the Aged, UK 2002, pp. 4-6.

8. PBourdieu. TheForms ofCapital, In:RichardsonJ.(Eds). Handbook of Theory and Research for the Sociology of Education. Greenwood Publishing Group, USA 1986, pp 46-58. (DOI:10.1002/9780470755679.ch15)

9. Saraceno C. Do we need a capital account for culture? Paper presented at the Joint IEA/ISI Strategic Forum 2014 and Workshop of the High-Level Expert Group on the Measurement of Economic Performance and Social Progress on Intra-generational and Inter-generational Sustainability. Rome, 22-23 September 2014. [Internet] Available from: https:// www.carloalberto.org/wp-content/uploads/2018/11/ no.367.pdf. Accessed: 12.07.2019.
10. Arun Ö. The Adventures of the Elderly in Turkey: Distribution of Cultural Capital Among the Elderly in Turkey. Gaziantep University Journal of Social Sciences 2008;7(2): 313-330. [Internet] Available from: https://dergipark.org.tr/en/download/articlefile/223481. Accessed: 10.07.2019. (in Turkish).

11. Arun Ö, Elmas Ç. Distinction in Old Age: Challenge Awaiting Local Authorities in Contemporary Turkey. Istanbul University Journal of Sociology 2016;36(2):351-372. [Internet] Available from: https://dergipark.org.tr/tr/pub/iusosyoloji/ issue/35801/401012. Accessed:15.10.2018. (DOI: 10.16917/iusosyoloji.291221). (in Turkish).

12. Barbara G. Tabachnick, Linda S. Fidell. Using Multivariate Analysis. 6th edition, Pearson, USA 2013, pp.33-46.

13. Duman B. Preliminary Assessments About Risks and Expectations in Urban Transformation: A Field Survey in Istanbul. Megaron 2015;10(3):410-22. [Internet] Available from: https://www.journalagent. $\mathrm{com} / \mathrm{megaron} / \mathrm{pdfs} / \mathrm{MEG} A R O N \_10 \_3$ 310_422. pdf. Accessed: 12.07.2019. (DOI: 10.5505/ MEGARON.2015.87993). (in Turkish)

14. Şentürk M, Kurtkapan $H$. The Spatialization of Old Age: A Qualitative Study on an Apartment Building in Kadıkoy's Moda District of Istanbul. J Aging Stud 2017;1(1):4-19. [Internet] Available from: https:// dergipark.org.tr/tr/download/article-file/400878 Accessed: 13.09.2018. (DOI: 10.24876/senex). (in Turkish).

15. Kleinhans $R$, Veldboer $L$, Jansen $S$, Van Ham M. Ageing in a long-term regeneration neighborhood: A disruptive experience or successful ageing in place? IZA Discussion Papers, No: 8660. 2014. [Internet] Available from: http://ftp.iza.org/dp8660. pdf. Accessed: 07.09.2017. 